\title{
Measuring Vocabulary Size of Japanese Junior High School Students: Cross-Sectional and Longitudinal Viewpoints
}

\author{
Tsuyoshi SATO \\ Hirosaki University
}

\begin{abstract}
The present study examines the current situation and development of the vocabulary size of Japanese junior high school students learning English at the beginner level using a vocabulary size test (Sato, 2016). A total of 505 of junior high school students participated in the research and their vocabulary size was measured at the end of the first and the second term. The results show that, at the end of the first term, junior high school students have significantly different vocabulary sizes depending on their grade levels, with an average estimated vocabulary size of 795.03 for seventh-grade, 1,024.59 for eighth-grade, and $1,070.76$ for ninth-grade. The acquisition process shows the different patterns for the various word frequency groups. For seventh graders, the 400 and 1,200 word groups developed significantly, while only the 1,200 word level increased significantly for eighth graders. Considering these results, further research is needed in order to state more precisely the process of vocabulary development of junior high school students as well as improvement of the test adopted in the present study.
\end{abstract}

Keywords: vocabulary size, test development, junior high school

To maximize the effectiveness of a certain teaching method, teachers should use teaching materials and techniques that have been developed based on second language acquisition (SLA) research findings. In English as a second language (ESL) or English as a foreign language (EFL), research in which teaching treatments or materials in use, along with measures and examination of the effectiveness is conducted, then based on the results, various kinds of teaching activities can be proposed (Celce-Murcia, Brinton, \& Snow, 2014; Nation, 2013). However, for Japanese junior high school students as beginning level English learners, little research has been conducted; accordingly teaching methods, activities, and materials used in the classrooms are mostly based on experience, even intuition, of the teachers who are in charge of the lessons. One of the reasons for the shortage of empirical research on junior high school students as subjects is that there are few standardized tests which are suitable to measure their skills or proficiency. That is to say, in empirical research, in most cases, subjects are divided into experimental and control groups, for which 
equivalency is confirmed using a pre-test in advance, and the target treatment under examination is operated for the experimental group for a certain duration. Then, the results of a post-test or a delayed-test are compared statistically with the results of the pre-test. In a case of research on adult learners, some standardized test are available such as Test of English as a Foreign Language (TOEFL), Test of English for International Communication (TOEIC) and so on. However, in empirical studies, it is convenient to use a vocabulary size test as a pre-test or a post-test. This is because the learners' vocabulary size is strongly related to their proficiency of the language suggested in several studies (Koda, 1989; Laufer, 1992; Meara, 1992). To conduct empirical research targeting junior high school students, it is assumed that the first step is to develop a vocabulary size test which can be used as a pre-test or a post-test.

Considering classrooms of Japanese junior high schools, a concept of vocabulary knowledge seems to be taken in quite a different way from that of language learning in general. That is, in junior high school lessons, each lesson or unit of textbook has some target vocabulary items as new words, which are introduced through teacher presentation or in a passage of the textbook, practiced within activities or exercises, and then checked using small quizzes at the end of lesson or the beginning of the next lesson. This spiral and accumulation is seen as building up the vocabulary knowledge of Japanese junior high school students. In this point of view, vocabulary tests usually indicate achievement in the context of the teaching setting of junior high school. However, since students' vocabulary knowledge includes items that they have learned in daily life, measurement of their total knowledge, not just the items taught in their texts, is required. The present study considers the possibility of measuring the vocabulary size of junior high school students and illuminating the process of their vocabulary acquisition.

\section{Literature Review}

As mentioned above, vocabulary size tests are important both in the field of research and education. This is because the learners' vocabulary size is strongly related to the proficiency of the language. In fact, much research has been conducted to measure learners' vocabulary size and propose that it strongly correlates with other language proficiency both in L1 and L2 (Arnauld, 1992; Koda, 1989; Laufer, 1992; Meara, 1996). As a result, a variety of vocabulary size tests have been developed and used as a standard of measuring learners' proficiency (Aizawa, 1998; Koizumi, 2003; Meara, 1992; Meara \& Buxton, 1987; Mochizuki, 1998; Nation, 1990, 2001, Sato, 2003; Schmitt, Schmitt, \& Clapham, 2001) and these are used in much empirical research as a means of confirming participants' equivalency before the research or to verify the target treatment as a post-test or a delayed-test comparing the experimental group and the control group. From this point of view, the vocabulary size test has an important role as a basis in the field of the empirical research of language learning or acquisition. In the field of education, the idea of vocabulary size is used as a criterion which learners are to have achieved after a certain course, as a level of class placement to show a suitable level for each student and as an indicator of material level which is of appropriate 
difficulty for learners.

From the above, much research has been conducted to measure and reveal the vocabulary size of learners at a certain level. According to Goulden, Nation, and Read (1990), in research for L1 learners as subjects, the vocabulary size of a well-educated adult native speaker of English is estimated at around 17,000 words. Furthermore, the receptive vocabulary knowledge of native speakers of English increases at the rate of 1,000 word families per year up to the age of twenty (Goulden et al., 1990). However, Nation (2001) suggests that results of research shows there is large variation, which seems to result from the participants' wide range of age and educational background and concludes that in research comparing the vocabulary size between native speakers and non-native speakers, the type of native speakers must be carefully examined.

Much research measuring L2 learners' vocabulary size as a subject also has been conducted (Alonso, 2013; Gallego \& Agustin Llach, 2009; Laufer, 1998; Qian, 2002). From the findings of the research, it is estimated that L2 learners of an intermediate level have around 1,000 words to 3,000 words, showing a wide range of variation again. As research on Japanese learners, Kosuge (2003) measured the vocabulary size of Japanese junior high school students using Vocabulary Size Test for Japanese Learners of English (Mochizuki, 1998) and concluded that the average vocabulary size of seventh-grade students was $1,185.97$, and that of eighth-grade students was $1,859.52$ at the end of the school year respectively. This vocabulary size is assumed to be reasonable considering the fact that 3,000 to 4,000 word families are needed for intermediate learners to get $95 \%$ coverage of various written texts, such as novels, newspapers and movies, Nation (2006) suggested as the first standard of the vocabulary size which English learners need to use English independently. The relationship between lexical coverage and comprehension of the text in listening tasks by 36 native and 40 non-native speakers as subjects was investigated by van Zeeland and Schmitt (2012), where the results show that 90 percent of lexical coverage is adequate to comprehend spoken passages. Thus, van Zeeland and Schmitt conclude that language users need to know 2,000 to 3,000 word families for adequate listening comprehension.

As above, the findings of various research propose that for L2 learners, it is valid to set a first goal to increase vocabulary size up to 2,000 to 3,000 word families. However, there is little research either on the present situation of vocabulary size of Japanese junior high school students as the beginning level of English learners examining the differences among the grades or on the process of their vocabulary development within each grade up to the 2,000 to 3,000 word families as the first standards to achieve as intermediate level of English users. The difficulty of such research using Japanese junior high school students results mainly from the lack of a suitable vocabulary size test for this target group. Although various vocabulary size tests have been developed and examined (Aizawa, 1998; Koizumi, 2003; Mochizuki, 1998; Nation, 1990, 2001), most are not considered suitable for the participants of the present study. Problems existing in these tests are as follows.

First, it is problematic to use any currently existing vocabulary size tests to measure the 
English proficiency of Japanese junior high school students considering their difficulty on the basis that these tests are targeted at measuring adult English learners' proficiency. In short, they are too difficult for Japanese junior high school students. As above, to examine either the current situation or process of development of vocabulary size closely, the adopted vocabulary size test needs to be appropriate to measure at a level under 2,000 to 3,000 word families, sub-dividing them to some levels according to their frequencies. However, even the lowest vocabulary levels of existing tests are too high for Japanese junior high school students. For example, the lowest level of the Vocabulary Size Test (Mochizuki, 1998), which is considered as the representative vocabulary size tests for Japanese learners, is set at 1,000 words.

Second, the characteristics of the word lists on which the vocabulary size tests are based need to be considered. That is, most of those vocabulary size tests are made with word lists based on authentic English used by native English speakers, such as The British National Corpus (BNC). Such tests are appropriate to measure learners' vocabulary size using authentic English as a point of reference because it implies how well learners comprehend English in the real world. However, it is questionable how valid a test based on a corpus of authentic English data is to measure the vocabulary size of Japanese junior high school students, because the characteristics of vocabulary of authentic English are different from those of vocabulary taught in junior high schools in Japan. No matter how frequently a word appears in natural conversation, students cannot be expected to know it if they don't learn it in their English class. Thus, it is more feasible to measure a learner's vocabulary size by using a test based on the word lists of authorized textbooks used by junior high school students in Japan.

Finally, and most importantly, to measure and examine the vocabulary size of Japanese junior high school students longitudinally, a vocabulary size test needs to be used repeatedly over a short duration. However, existing vocabulary size tests have a limited number of formats. This is because these tests are designed mainly as proficiency tests meant to measure learners' vocabulary size at a single point in time. They are not designed for research to measure learners' vocabulary size again and again.

Considering the characteristics of the present vocabulary size tests, Sato (2009) developed the vocabulary size based on the word list gained from the authorized textbooks used in Japan. The vocabulary size test adopts a Computer Based Testing (CBT) system so that it can be used repeatedly with the same learners in a short span of time. In the vocabulary size test, test items are randomly extracted from the word list. This means that each time the test is taken, different test items would be used, and it could thus be taken multiple times by the same test taker. Sato (2010) examined the test format, such as the clarity of instructions, the layout of the choices and the distracters for a small number of subjects. However, the biggest obstacle to designing a vocabulary size test with the characteristics described above is in its reliability. That is, the difficulty of the test may change depending on the choices and the distracters randomly generated from the word list. Therefore, pilot studies have been 
conducted to examine the reliability of the vocabulary test (Sato, 2009) and based on the results, the test has been revised as a process described as follows.

Sato (2011) conducted research to examine whether the vocabulary test (Sato, 2009) is able to be used equally for the subjects who use the three different authorized textbooks. The results showed that the test can be used even if students use different textbooks. However, there was a significant difference between the two forms of the test for all three groups, which shows that, in the current system, the difficulty of this test may change each time the test items are drawn out of the item bank, showing the balance of high frequency words extracted from the word list are strongly related to the difficulty of the test; the more the test includes high frequency words extracted, the easier it becomes, and vice versa. Therefore, a revised version of the vocabulary size test was programmed so that the high frequency words are extracted at the same ratio every time.

Sato (2016) conducted research to examine the reliability of the revised version of the vocabulary size test addressed above. In the study, the 1,000 word level Vocabulary Size Test (Mochizuki, 1998), which is currently considered as one of the most valid and reliable vocabulary size tests, was also conducted to examine the criterion-referenced validity of the developing vocabulary size test. The results of the revised pilot test confirm that the level of difficulty for different forms of each level of the test is maintained, showing there was no significant differences among the different forms randomly generated by the computer program and strong correlation ( $r=.70$ to .74 ) with Vocabulary Size Test (Mochizuki, 1998). This indicates that the test is one step closer to being able to be used practically in English classrooms or empirical research.

\section{The Present Study}

Considering the previous research, the vocabulary size which is necessary for L2 learners to comprehend English adequately in listening and reading has been identified as 2,000 to 3,000 word families as their first goal of the vocabulary learning (Nation, 2001, 2013; Nation \& Webb, 2011). However, in terms of the vocabulary size of Japanese junior high school students, their starting point, how much vocabulary they have at the beginning of their school year as well as the process of the development and how their vocabulary size increases have not yet been identified. Therefore, it is important to conduct the further research to examine the vocabulary size of Japanese junior high school students either in cross-sectional or longitudinal method. Therefore, the present study is conducted with the following objectives:

(1) To measure the vocabulary size of junior high school students in a cross-sectional method; correlating their size with their grades.

(2) To examine the process of vocabulary size development by measuring the vocabulary size of junior high school students longitudinally, comparing their vocabulary size of the first term and that of the second term of their school year. 


\section{Method}

\section{Procedure}

The present research examines the current vocabulary size of Japanese junior high school through the two related studies described below. Study I, to measure the initial vocabulary size of the junior high school students was administered in July 2016, measuring three frequency levels using the vocabulary size test developed by Sato (2016). One level was administered per session allowing them sufficient time to finish the whole test. The approximate testing time was 15 minutes per session.

Study II measured the vocabulary size of the students at the end of the second term which was then compared to the results of the July administration conducted in December 2016. The test items shown in the vocabulary size tests for the same frequency levels were different in each study, since the test items were randomly extracted from the word list item bank (Sato, 2016).

To measure the vocabulary size of the participants longitudinally, the test should have been conducted in April and March and their results should have been compared. However, because of various schedule constraints, the first testing was conducted in July and the second one in December.

\section{Participants}

A total of 505 Japanese junior high school students from a junior high school attached to Hirosaki University participated in Study I, which was conducted in July. They were divided into three groups according to their grade; seventh-grade $(n=161)$, eighth-grade $(n=$ $156)$, and ninth-grade $(n=188)$. All participants have studied English from the first grade in the elementary school attached to Hirosaki University using authorized junior high school textbooks.

For Study II, the participants were 317 Japanese junior high school students from the same junior high school, 161 seventh-grade students and 156 eighth-grade students. Unfortunately, the ninth-grade students were not able to participate in Study II due to their preparation of their entrance examinations.

\section{Materials}

The experiment used the vocabulary size test which was developed from the vocabulary list based on the authorized textbooks used in Japanese English classes outlined above (Sato, 2016). This vocabulary size test consists of three levels: Level 1 (400 word level), Level 2 (800 word level), and Level 3 (1,200 word level). Every test consists of words randomly extracted from the item bank. Thus, the test used in July and the one used in December produced different vocabulary items, even in the same level. 


\section{Data Analysis}

Study I was to examine the vocabulary size of the junior high school students in the first term of their school year and the difference among their grades, regarding objective (1). The average vocabulary sizes estimated from the result of the vocabulary size test were compared using a one-way analysis of variance (ANOVA). The effect sizes were calculated by partial eta squared $\left(\eta_{\mathrm{p}}{ }^{2}\right)$. In addition, item discrimination (ID) analysis was conducted to observe the characteristics of their vocabulary knowledge in detail.

Study II was to compare the vocabulary size measured in July and December by each grade, addressing objective (2). Two-way ANOVAs were conducted for each grade, considering the test time (July and December) and the levels of vocabulary size (400 word level, 800 word level, and 1,200 word level) as independent variables.

\section{Results and Discussion}

\section{Study I: The Differences in the Vocabulary Size Test Among the Grades}

The descriptive statistics of the vocabulary size test (Sato, 2016) by the grades of the participants are presented in Table 1 . The average estimated vocabulary size for each grade was 795.03 for seventh-graders, 1,024.59 for eighth-graders, and 1,070.76 for ninth-graders. According to the current course of study of Japanese government, the number of vocabulary items which are to be taught in junior high school is 1,200 words. Considering this standard, the estimated vocabulary sizes of the participants of the present study is concluded to be quite large, with even the seventh-graders of July; at the beginning term of studying English in their junior high school, having a vocabulary size estimated to represent more than half of the vocabulary size offered in the current course of study.

Table 1

Descriptive Statistics for Vocabulary Size Test $(\mathrm{N}=505)$

\begin{tabular}{lcccrc}
\hline \multicolumn{1}{c}{ Group } & $n$ & $\alpha$ & $M$ & \multicolumn{1}{c}{$S D$} & $95 \%$ CI \\
\hline 7th grader & 161 & .90 & 53.66 & 14.40 & {$[52.52,54.80]$} \\
8th grader & 156 & .89 & 69.16 & 7.23 & {$[68.58,69.73]$} \\
9th grader & 188 & .86 & 72.27 & 7.03 & {$[71.76,72.79]$} \\
\hline
\end{tabular}

Note. The maximum score for the vocabulary size test (Sato, 2010) is 81 .

Moreover, according to the results of vocabulary sizes of eighth and ninth graders, ceiling effects were observed as presented in Figure 1, implying that their vocabulary sizes are more than 1,200 words, which is the maximum vocabulary size of the vocabulary size test (Sato, 2016). This indicates that it is necessary to develop a vocabulary size test which is capable of measuring more than 1,200 words for junior high school students, as well as examining the validity of using a standard of 1,200 words as the number of vocabulary items to be presented in their curriculum.

The results of a one-way ANOVA comparing the mean scores of the three different 
grades are presented in Table 2. There was a significant difference in the grades, $F(2,502)=$ $165.3, p<.001, \eta_{\mathrm{P}}^{2}=.04$. Tukey's multiple comparison showed that there were significant differences among all three grades, between seventh and eighth graders $(p<.001, d=1.35)$, between seventh and ninth graders $(p<.001, d=1.68)$, and between eighth and ninth graders $(p<.001, d=0.44)$. The differences in the mean scores between seventh and eighth graders and seventh and ninth graders are significant and the effect size is large. However, as mentioned above, the result seems to be influenced by a ceiling effect on the results of the scores of eighth-graders and ninth-graders. From the fact that even though there seems to be a ceiling effect, a significant difference is observed between them, and therefore it is valid to conclude that there are differences in the vocabulary sizes among grades of junior high school students.

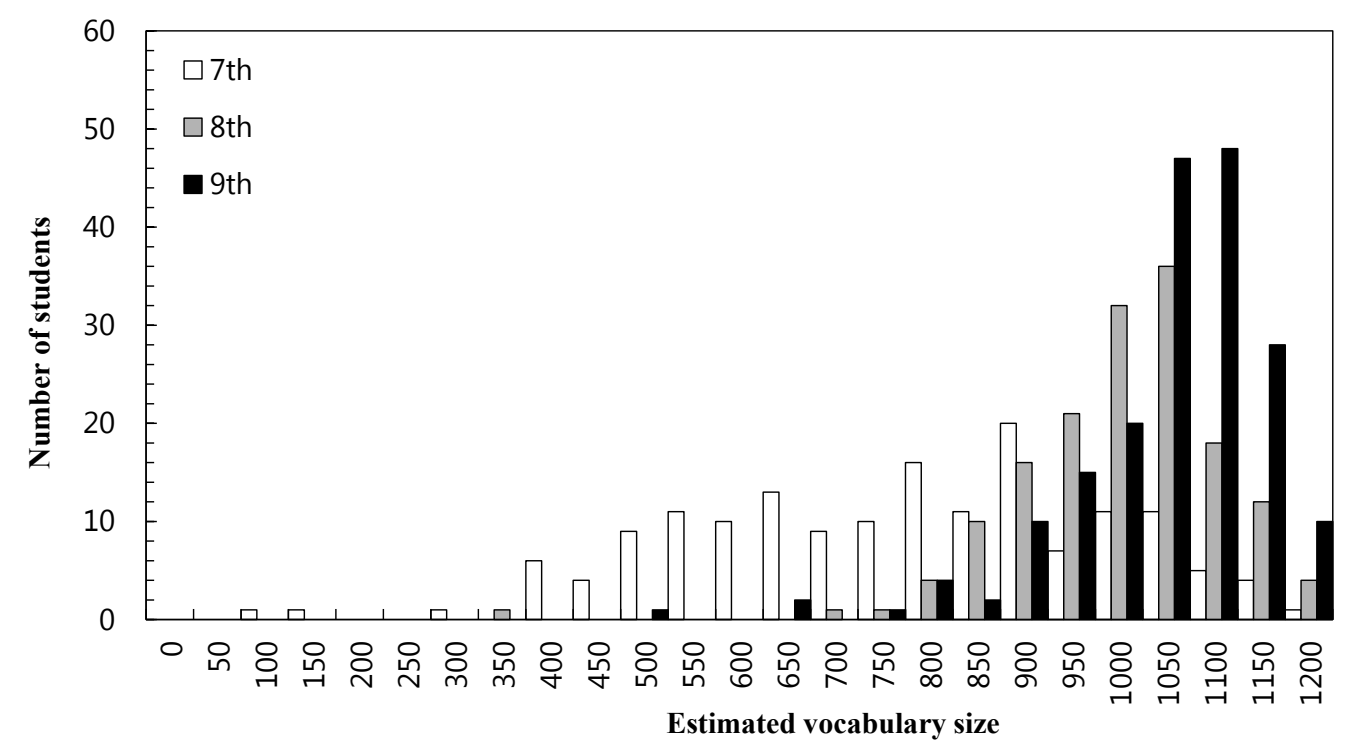

Figure 1. The distribution of estimated vocabulary size.

Table 2

Results of the One-Way ANOVA for the Vocabulary Size Test

\begin{tabular}{lrrrrrr}
\hline \multicolumn{1}{c}{ Sources } & \multicolumn{1}{c}{$S S$} & \multicolumn{1}{c}{$d f$} & \multicolumn{1}{c}{$M S$} & \multicolumn{1}{c}{$F$} & $p$ & $\eta_{\mathrm{P}}{ }^{2}$ \\
\hline Grades & 33268.50 & 2 & 16634.25 & 165.03 & $<.001$ & .40 \\
Error & 50598.50 & 502 & 100.79 & & & \\
Total & 83867.00 & 504 & & & & \\
\hline
\end{tabular}

\section{Results of Item Discrimination (ID) Analysis}

To examine the test results in more detail, the ID was calculated by each test item. The test items of which ID were under .20 are shown below. A low ID figure implies that either the test item was too easy or too difficult for the test-takers. However, in the case of the 
present study, all of the test items shown below with a low score of ID were caused by the items being too easy for the participants.

(1) Level 1 (400 words): and, dream, brother, homework, left, answer, game, class, food, town, July, or, station, star, bike, thank

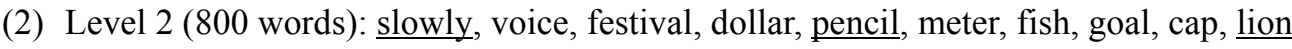

(3) Level 3 (1,200 words): bowl, soup, grandpa, jazz, volleyball, sleepy truck

The underlined test items are what the participants are taught and used at the point of the time when the vocabulary size test was conducted, showing that a few words are learnt from their textbooks. This finding suggests that students learned many more vocabulary items from sources other than the textbooks, which can be loan words used in their daily lives, and even the seventh-graders have large size of English vocabulary. Thus, it is quite probable that students of seventh-grade have a certain amount of receptive vocabulary knowledge, and at least they can understand them, and therefore it is efficient to make use of loan words in teaching at the beginning level. This suggests that it might be feasible to conduct English classes using only English from very early levels taking advantage of the loan words that they already know.

\section{Study II-1: The Comparison of Vocabulary Size of Seventh-Graders in July and December}

The descriptive statistics of the vocabulary size test for seventh-graders by the three levels conducted in July and December are presented in Table 3. It seems that even though the vocabulary size of the participants increases in all the three levels, there is a differencein the degree of the development among the three levels and the grades of the participants.

Table 3

Descriptive Statistics for Vocabulary Size Test of the Seventh-grader $(\mathrm{N}=161)$

\begin{tabular}{lccccccc}
\hline & \multicolumn{3}{c}{ July } & & \multicolumn{3}{c}{ December } \\
\cline { 2 - 3 } Level of difficulty & $M$ & $95 \%$ CI & $S D$ & & $M$ & $95 \%$ CI & $S D$ \\
\hline 400 words level & 20.75 & {$[20.37,21.12]$} & 4.73 & & 22.83 & {$[22.56,23.09]$} & 3.37 \\
800 words level & 18.40 & {$[17.99,18.82]$} & 5.31 & & 19.05 & {$[18.65,19.44]$} & 4.98 \\
1,200 words level & 14.50 & {$[14.07,14.93]$} & 5.49 & & 16.80 & {$[16.34,17.24]$} & 5.68 \\
\hline
\end{tabular}

Note. The maximum score for each level of the vocabulary size test (Sato, 2010) is 27. 
Table 4

Results of the Two-Way ANOVA for the Vocabulary Size Test of the Seventh-Graders

\begin{tabular}{lrrrrrr}
\hline \multicolumn{1}{c}{ Sources } & \multicolumn{1}{c}{$S S$} & \multicolumn{1}{c}{$d f$} & \multicolumn{1}{c}{$M S$} & \multicolumn{1}{c}{$F$} & \multicolumn{1}{c}{$p$} & $\eta_{\mathrm{P}}{ }^{2}$ \\
\hline Levels & 6069.17 & 2 & 3034.58 & 122.20 & $<.001$ & .20 \\
Test Time & 672.501 & 1 & 672.50 & 27.08 & $<.001$ & .02 \\
Interaction & 129.7536 & 2 & 64.87 & 2.61 & .074 & .00 \\
Error & 23838.22 & 960 & 24.83 & & & \\
Total & 30709.65 & 965 & & & & \\
\hline
\end{tabular}

Table 4 shows the results of a two-way ANOVA, comparing the mean scores with standard deviations between the test time and the three levels of the vocabulary size test for seventh-graders. The results show that there were significant differences between the main effect at the three levels, $F(2,960)=122.20, p<.001, \eta_{\mathrm{P}}{ }^{2}=.02$; test time, $F(1,960)=27.08$, $p<.001, \eta_{\mathrm{P}}^{2}=.02$. However, there was no significant difference in the interaction of the levels and the test time, $F(2,960)=2.61, p=.074, \eta_{\mathrm{P}}^{2}=.00$.

Each main effect was examined and there were significant differences among all three levels, showing that each level measures different knowledge of the participants. This confirms that the validity of the three level setting of the vocabulary size test (Sato, 2016).

The results of analysis of the main effect for the two administrations shows that, for the seventh-graders, their vocabulary size grew significantly in the 400 word level $(p<.001, d=$ $0.51)$, and in the 1,200 word level $(p<.001, d=0.41)$ between July and December. However, there was no significant difference between the two test times for the 800 word level $(p$ $=.249, d=0.13)$. In general, it is easily assumed that the vocabulary size of learners increases from the easy level; in another words, their acquisition starts and proceeds from high frequency words to low frequency ones, such as from words nominated in 400 word level to words in 1,200 word level in the vocabulary test adopted in the present study. However, the results of the present study, presenting the vocabulary size of 400 word level and 1,200 word level, can be interpreted as meaning that, students of seventh-grade mainly learn and acquire the vocabulary size of 400 word level at this point. However, the mean score of the vocabulary size test of the 1,200 word level was very small in the first term, at 14.50, about half of the test, so even small development of vocabulary size of this level results in significant differences statistically. These results show the characteristics of the vocabulary learning of seventh-graders through their school year.

\section{Study II-2: The Comparison of Vocabulary Size of Eighth-Graders in July and December}

The descriptive statistics of the vocabulary size test for eighth-graders by the three levels conducted in July and December are presented in Table 5. Considering the maximum score of the vocabulary size test is 27 , they can understand the vocabulary items of 400 and 800 word level almost perfectly, showing a mean score of 26.44 for the 400 word level and 
23.94 for the 800 word level. This indicates that by the eighth-grade students have already acquired almost all the 800 level words receptively.

Table 5

Descriptive Statistics for the Vocabulary Size Test of the Eighth-Graders $(\mathrm{N}=156)$

\begin{tabular}{lccccccc}
\hline & \multicolumn{3}{c}{ July } & & \multicolumn{3}{c}{ December } \\
\cline { 2 - 3 } Level of difficulty & $M$ & $95 \%$ CI & $S D$ & & $M$ & $95 \%$ CI & $S D$ \\
\hline 400 words level & 26.10 & {$[25.94,26.24]$} & 1.91 & & 26.44 & {$[26.25,26.62]$} & 2.30 \\
800 words level & 23.58 & {$[23.33,23.81]$} & 3.02 & & 23.94 & {$[23.65,24.22]$} & 3.55 \\
1,200 words level & 19.49 & {$[19.18,19.78]$} & 3.77 & & 21.74 & {$[21.41,22.06]$} & 4.08 \\
\hline
\end{tabular}

Note. The maximum score for each level of the vocabulary size test (Sato, 2010) is 27.

Table 6 shows the results of a two-way of ANOVA, comparing the mean scores with standard deviations between the test time and the three levels of the vocabulary test for the eighth-graders. The results show that there were significant differences between the main effect of the three levels, $F(2,930)=244.43, p<.001, \eta_{\mathrm{P}}^{2}=.034$; test time, $F(1,930)=$ $22.14, p<.001, \eta_{\mathrm{P}}^{2}=.02$; in the interaction of the levels and the test time, $F(2,930)=9.12, p$ $<.001, \eta_{\mathrm{P}}^{2}=.02$. This indicates that the vocabulary size of eighth-graders increases differently among the levels and between the test times. To examine this in detail, the main effects were analyzed using a Post hoc analysis. As shown in the results of the seventh-graders, the results of Turkey's multiple comparison show that there were also significant differences among all of three levels in the vocabulary size for eighth-graders. Again, the results confirm the validity of the three level setting of the vocabulary size test for the different levels of participants.

Table 6

Results of the Two-way ANOVA for Vocabulary Size Test of the Eighth-Grader

\begin{tabular}{lrrrrrr}
\hline \multicolumn{1}{c}{ Sources } & \multicolumn{1}{c}{$S S$} & \multicolumn{1}{c}{$d f$} & \multicolumn{1}{c}{$M S$} & \multicolumn{1}{c}{$F$} & \multicolumn{1}{c}{$p$} & $\eta_{\mathrm{P}}{ }^{2}$ \\
\hline Levels & 5013.07 & 2 & 2506.54 & 244.43 & $<.001$ & .34 \\
Test Time & 227.05 & 1 & 227.05 & 22.14 & $<.001$ & .02 \\
Interaction & 187.22 & 2 & 93.61 & 9.12 & $<.001$ & .02 \\
Error & 9536.67 & 930 & 10.25 & & & \\
Total & 14964.02 & 935 & & & & \\
\hline
\end{tabular}

However, in the main effect for the test times of the eighth-graders, significant differences can be found only in the 1,200 word level $(p<.001, d=0.57)$, and no significant differences can be found either in 400 word level $(p=.340, d=0.16)$ or 800 word level ( $p$ $=.322, d=0.11$ ). These findings suggest that in the vocabulary growth of eighth-graders, they already have enough vocabulary to understand receptively at the 400 word level and the 
800 word level, thus only the vocabulary knowledge of 1,200 word level increases in the stage of eighth-grade. However, as above, it is probable that the participants' vocabulary knowledge exceeds 1,200 word level even among eighth-graders, showing the results have a ceiling effect. Therefore, it is important to develop a vocabulary size test which can measure a higher word level for junior high school students in order to examine how the vocabulary size of junior high school students develops after this level, such as at the time of ninth-grade.

From these results, it can be assumed that the vocabulary size of junior high school students increases unevenly with regard to word frequency levels. From these findings we can hypothesize that the growth in the vocabulary size of junior high school students suggested are as follows. First, they already have some amount of vocabulary size even in the first term of junior high school. Their vocabulary size can be estimated at around 800 words. This vocabulary knowledge originated mostly in loan words. Then during seventh-grade, they increase their vocabulary knowledge at the 400 word level and the 1,200 word level mainly. In eighth-grade, they have approximately a 1,000 vocabulary size and they have sufficient receptive vocabulary knowledge in the 400 word level and 800 word level, then during the year, their vocabulary size increases mostly in the 1,200 word level. However, in the present study, it is so far unclear when they develop their vocabulary knowledge at the 800 word level. Further research needs to be conducted to measure and examine the vocabulary size of Japanese junior high school students in shorter durations.

\section{Conclusion}

The present study examined the current situation and the development of the vocabulary size of Japanese junior high school students learning English at the beginner level. It aims at confirming the measurement of vocabulary size itself and to the improvement of English curricula. The vocabulary size test (Sato, 2016), which was designed specifically for junior high school students, measured their vocabulary of the first term and second term of their school year at each grade level. The results indicate that, at the end of the first term, junior high school students have different vocabulary sizes according to their grade levels, showing an average of estimated vocabulary sizes for each grade as 795.03 for seventh-graders, 1,024.59 for eighth-graders, and 1,070.76 for ninth-graders. This indicates that junior high school students have a certain amount of vocabulary knowledge from the beginning of their school year, and their vocabulary size increases up to more than 1,000 words through eighth and ninth-grade. The process of vocabulary acquisition shows an interesting implication, showing the different tendency of growth among the level of words of frequency: for seventh-grade, the vocabulary knowledge of 400 and 1,200 words levels develops significantly, whereas, only the vocabulary knowledge of 1,200 word level increases significantly for eighth-graders. This research thus provides evidence for more effective choices of teaching methods and materials.

However, as mentioned above, the vocabulary size of eighth and ninth-graders are probably larger than the coverage of the vocabulary size test adopted in the present study 
(1,200 words). This suggests that it is necessary to revise the vocabulary test to make it capable of measuring a larger vocabulary size. Moreover, the timing at which the vocabulary size of 800 word level for junior high school students develops could not be identified in the present study. Future research, conducted in shorter duration and measuring the vocabulary size throughout three years, is necessary to reveal vocabulary knowledge in both current situation and the vocabulary acquisition process.

\section{Acknowledgements}

I would like to thank Kahoko Matsumoto, Anthony S. Rausch, and two anonymous reviewers for their constructive comments and suggestions on an earlier draft.

\section{References}

Aizawa, K. (1998). Developing a vocabulary size test for Japanese EFL learners. ARELE: annual review of English language education in Japan, 9, 75-85. doi:10.20581/ arele.9.0_75

Alonso, A. C. (2013). Receptive vocabulary size of Spanish secondary EFL learners. Revista de Lingüistica y Lenguas Aplicadas, 8, 66-75. doi:10.4995/rlyla.2013.1180

Arnaud, P. J. (1992). Objective lexical and grammatical characteristics of L2 written compositions and the validity of separate-component tests. In P. J. L. Arnaud \& H. Béjoint (Eds.), Vocabulary and applied linguistics (pp. 133-145). London, England: Macmillan.

Celce-Murcia, M., Brinton, D., \& Snow, M. A. (2014). Teaching English as a second or foreign language. Boston, MA: National Geographic Learning.

Gallego, M. T., \& Agustin Llach, M. P. (2009). Exploring the increase of receptive vocabulary knowledge in the foreign language: A longitudinal study. International Journal of English Studies, 9, 113-133. Retrieved from http://revistas.um.es/ijes/ article/viewFile/9 0681/87481

Goulden, R., Nation, P., \& Read, J. (1990). How large can a receptive vocabulary be? Applied Linguistics, 11, 341-363. doi:10.1093/applin/11.4.341

Koda, K. (1989). The effects of transferred vocabulary knowledge on the development of L2 reading proficiency. Foreign Language Annals, 22, 529-540. doi:10.1111/j.19449720.1989.tb02780.x

Koizumi, R. (2003). A productive vocabulary knowledge test for novice Japanese learners of English: Validity and its scoring methods. JABAET Journal, 7, 23-52. Retrieved from http://www7b.biglobe.ne.jp/ koizumi/Productive_VKT_JABAET.pdf

Kosuge, A (2003). Goi-size-test kara mita goi no shutoku [Vocabulary development from the perspectives of a vocabulary size test]. In H. Ota, A. Kosuge, K. Kanatani, \& S. Hidai (Eds.), Eigoryoku ha donoyouni shite nobite ikuka: Chugakuseino eigo shutoku kateiwo ou [How English proficiency develops: Examining the process of English acquisition of junior high school students] (pp. 81-115). Tokyo, Japan: Taishukan. 
Laufer, B. (1992). How much lexis is necessary for reading comprehension? In P. J. L. Arnaud \& H. Béjoint (Eds.), Vocabulary and applied linguistics (pp. 126-132). London, England: Macmillan.

Laufer, B. (1998). The development of passive and active vocabulary in a second language: Same or different? Applied Linguistics, 19, 255-271. doi:10.1093/applin/19.2.255

Meara, P. (1992). EFL vocabulary tests. Centre for Applied Language Studies, University College Swansea.

Meara, P., \& Buxton, B. (1987). An alternative to multiple choice vocabulary tests. Language Testing, 4, 142-151. doi:10.1177/026553228700400202

Mochizuki, M. (1998). Nihonjin eigo gakushusha no tameno goi size test [A vocabulary size test for Japanese learners of English]. IRLT Bulletin, 12, 27-53. Retrieved from http://ci. nii.ac.jp/naid/40004654197

Nation, I. S. P. (1990). Testing and learning vocabulary. Boston, MA: Heinle \& Heinle.

Nation, I. S. P. (2001). Learning vocabulary in another language. Cambridge University Press.

Nation, I. S. P. (2006). How large a vocabulary is needed for reading and listening? Canadian Modern Language Review, 63, 59-82. doi:10.3138/cmlr.63.1.59

Nation, I. S. P. (2013). What should every ESL teacher know. Seoul, Korea: Compass.

Nation, I. S. P., \& Webb, S. (2011). Researching and analyzing vocabulary. Boston, MA: Heinle Cengage Learning.

Qian, D. D. (2002). Investigation the relationship between knowledge and academic reading performance: An assessment perspective. Language Learning, 52, 513-536. doi:10.1111/1467-9922.00193

Sato, R. (2003). Developing the vocabulary size test for junior high school and high school students according with the new course of study. STEP BULLETIN, 15, 25-37. Retrieved from https://www.eiken.or.jp/center_for_research/pdf/bulletin_archives/vol_15.pdf

Sato, T. (2009). Developing an English vocabulary size test for Japanese junior high school students: Through the process of compiling a word list. The Bulletin of the Center for Educational Research and Practice, Faculty of Education, Hirosaki University, 8, 2130.

Sato, T. (2010). Developing an English vocabulary size test for Japanese junior high school students: Through the pilot testing. The Bulletin of the Center for Educational Research and Practice, Faculty of Education, Hirosaki University, 9, 37-49.

Sato, T. (2011). Developing an English vocabulary size test for Japanese junior high school students: Through the analysis of the pilot testing. The Bulletin of the Center for Educational Research and Practice, Faculty of Education, Hirosaki University, 10, 3342.

Sato, T. (2016). Developing an English vocabulary size test for Japanese junior high school students: Examination of validity and reliability. TELES Journal, 36, 107-118.

Schmitt, N., Schmitt D., \& Clapham, C. (2001). Developing and exploring the behavior of 
two new versions of the vocabulary levels test. Language Testing, 18, 55-88. doi:10.1177/026553220101800103

van Zeeland, H., \& Schmitt, N. (2012). Lexical coverage in L1 and L2 listening comprehension: The same or different from reading comprehension? Applied Linguistics, 34, 457-479. doi:10.1093/applin/ams074 


\section{Appendix}

Sample of the Vocabulary Size Test of Level 1

\section{Vocabulary Size Test for JHS LEVEL 1 (400words)}

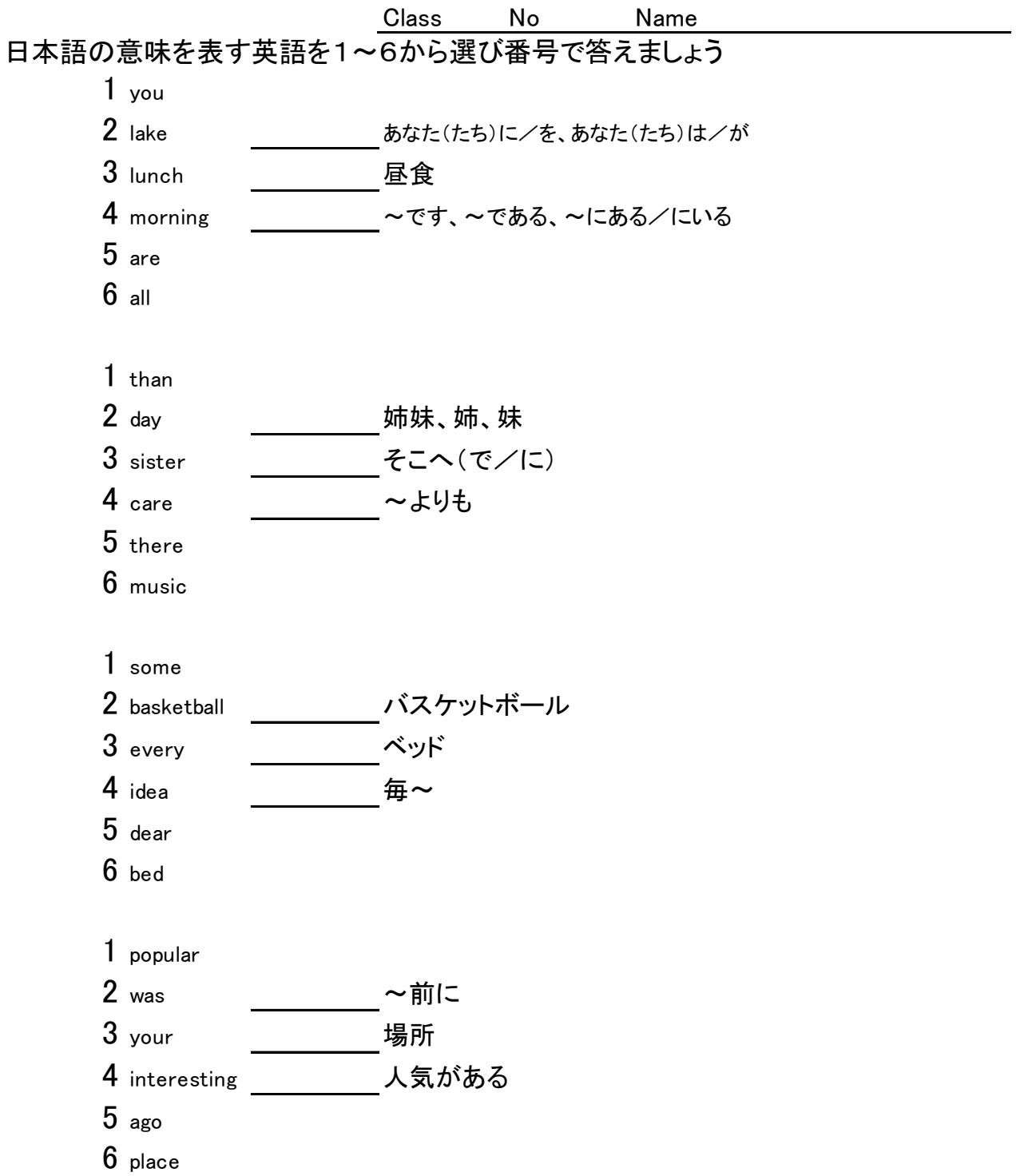




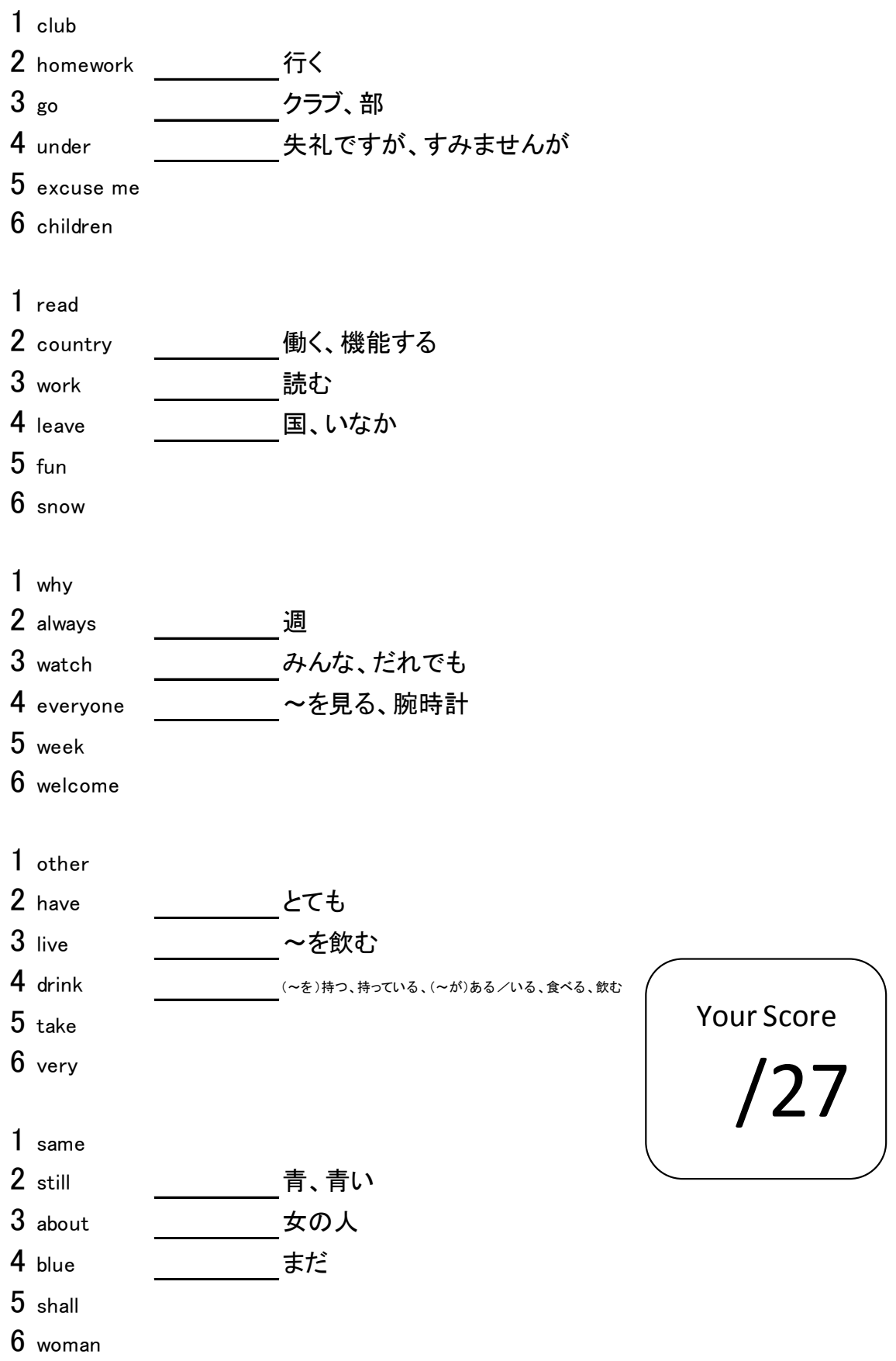

